\title{
Prediction of the Fragmentation Pathway of Atorvastatin De-Protonated Ion
}

\author{
Dev Kant Shandilya ${ }^{1^{*}}$, Rekha Israni1, Peter Edward Joseph ${ }^{2}$ \\ ${ }^{1}$ Department of Research, Bhagwant University, Ajmer, India \\ ${ }^{2}$ Department of Chemistry, ST. Johns College, Agra, India \\ Email: *shandilya@yahoo.com, *devkantshandilya@hotmail.com
}

How to cite this paper: Shandilya, D.K., Israni, R. and Joseph, P.E. (2018) Prediction of the Fragmentation Pathway of Atorvastatin De-Protonated Ion. Open Access Library Journal, 5: e4547. https://doi.org/10.4236/oalib.1104547

Received: March 26, 2018

Accepted: May 22, 2018

Published: May 25, 2018

Copyright ( $\odot 2018$ by authors and Open Access Library Inc.

This work is licensed under the Creative Commons Attribution International License (CC BY 4.0).

http://creativecommons.org/licenses/by/4.0/

(c) (i) Open Access

\begin{abstract}
Introduction: A fragmentation pathway of atorvastatin de-protonated ion was proposed based on rational interpretation workflows. Method: The mass spectral data (MS, MS/MS and $\mathrm{MS}^{3}$ ) of atorvastatin was obtained by electrospray negative ionization mode with flow injection analysis; using liquid chromatography systems coupled with tandem mass spectrometers (Q-trap and Q-ToF). Results: The fragmentation pathway was established using fragment ions of de-protonated ion; elemental composition, molecular structure and mechanism of formation for each major fragment presented. Pathway was proposed based on the $\mathrm{MS}^{3}$ spectral data in combination with basic interpretation rules and rational workflows. Conclusion: This study and data interpretation workflows can be useful for writing fragmentation pathway, mechanism for formation of fragments, and can be applied for mass spectral data interpretation of similar small organic molecules.
\end{abstract}

\section{Subject Areas}

Analytical Chemistry

\section{Keywords}

Atorvastatin, Small Drug Molecule, Fragmentation Pathway, De-Protonated Ion, High Resolution Mass Spectrometry, Fragmentation, Interpretation

\section{Introduction}

Mass spectrometry (MS) is an analytical technique/tool to identify and quantify verity of organic, inorganic and biological compounds. In pharmaceutical research and development, mass spectrometry plays a key role during development phases for all type of drug molecules: small organic molecules and large 
molecules (peptides and monoclonal antibodies). Use of advanced mass spectrometry instruments is continuously increasing in analytical research laboratories. These recent advance features along with rational workflows allow researchers for in-depth research with minimum experiments. In this study, spectral data generated using advanced mass spectrometric systems, along with rational data interpretation, is very helpful for detailed structural analysis study, i.e. to study the fragments and to propose a pathway [1]-[13] A focus of this study solely towards the mass spectral data interpretation, during this study high-resolution mass analyzer (Q-ToF) and unit resolution tandem mass analyzer (Q-trap) mass spectrometry systems with trap functionality, was used. Q-trap analyzer was very helpful to generate $\mathrm{MS}^{3}$ spectral data by using third quadrupole as trap, and high resolution mass analyzer Q-ToF provides the accurate $\mathrm{m} / \mathrm{z}$ information. $\mathrm{MS}^{3}$ information guided to write a fragmentation pathway for parent and product ions. A nitrogen-containing small organic molecule with hydroxyl, amide and carboxylic acid functional group atorvastatin was selected for this study and spectral data was generated using negative ion mode. Followed by prediction of fragmentation pathway of de-protonated ion, pathway of positive ion mode, i.e. protonated ion, was already published [14].

Atorvastatin [15] [16] [17] is an inhibitor of 3-hydroxy-3-methylglutaryl-coenzyme A (HMG-CoA) reductase. This enzyme catalyzes the conversion of HMG-CoA to mevalonate, an early and rate-limiting step in cholesterol biosynthesis. It is used primarily as a lipid-lowering agent and for prevention of events associated with cardiovascular disease, especially people with Type 2 Diabetes, coronary heart disease, or other risk factors. It is an off-white crystalline powder and chemically known as (3R, 5R)-7-[2-(4-Fluorophenyl)-3-phenyl-4-(phenylcarbamoyl)-5-propan-2-ylpyrrol-1-yl] -3,5-dihydroxyheptanoic acid. The empirical formula of atorvastatin calcium trihydrate is $\left(\mathrm{C}_{33} \mathrm{H}_{34} \quad \mathrm{FN}_{2} \mathrm{O}_{5}\right) 2 \mathrm{Ca} \cdot 3 \mathrm{H}_{2} \mathrm{O}$ and its molecular weight is 1209.42 . Atorvastatin free form empirical formula is $\mathrm{C}_{33} \mathrm{H}_{35} \mathrm{FN}_{2} \mathrm{O}_{5}$; monoisotopic molecular weight is 558.2530 and molecular structure of atorvastatin free form is presented in Figure 1.

During this study, mass spectral data of atorvastatin was generated using electrospray ionization and collision induced dissociation; followed by interpretation, workflow [18] and basic rules were used for the interpretation of the full scan atmospheric pressure ionization mass spectra (MS), collision induced dissociation fragmentation spectra (MS/MS) and $\mathrm{MS}^{3}$ data.

\section{Experimental}

\subsection{Drug Sample}

Atorvastatin was extracted from generic dosage form. A final concentration was about $10 \mu \mathrm{g} / \mathrm{ml}$ in water, methanol and acetonitrile.

\subsection{Chemicals and Reagents}

The ultrapure water (18.2 M $\Omega$ ) was obtained using MilliQ apparatus from Millipore (Milford, USA), acetonitrile HPLC grade and the HPLC grade methanol 


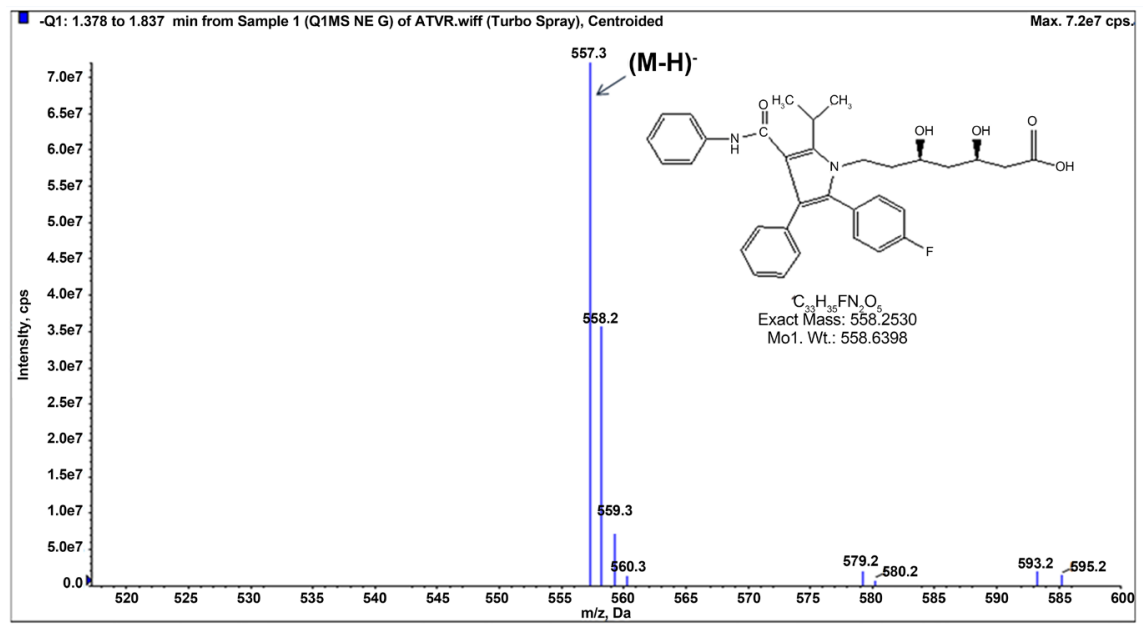

Figure 1. Deprotonated ion Atorvastatin in negative ion mode.

was purchased from J.T. Baker.

\subsection{Instrumentation}

Prominence 20 AD HPLC (Kyto Japan) and Waters Aquity HClass was coupled with Q-trap 5500 (AB SCIEX) and Xevo Q ToF mass spectrometer system respectively, equipped with electrospray ionization source (ESI) was used for this analysis.

\subsection{Chromatographic and Mass Spectrometric Conditions}

The extracted drug sample of atorvastatin was subjected to MS, MS/MS and $\mathrm{MS}^{3}$ analysis via flow injection analysis (FIA) mode; liquid chromatography system was used to introduce the sample to mass spectrometer ion source. Liquid chromatography system set to isocratic flow $0.1 \mathrm{ml} / \mathrm{min}$ of mobile phase water and methanol in a ratio of 1:1 and injection volume was $10 \mu$ l. Electrospray ion source (negative ion mode) was selected to achieve the intense de-protonated parent ion and Q-trap mass analyzer selected to get the MS, MS/MS and MS 3 ; which supported to predict the right fragmentation pathway. Spray voltage and collision energy optimized by using direct infusion mode to get optimum quality to spectral data. Experiments were acquired using optimized parameters; spray voltage of $-4.0 \mathrm{kV}$ for MS and collision energy (CE) setting of $40 \mathrm{~V}$ applied to generate $\mathrm{MS} / \mathrm{MS}$ and $\mathrm{MS}^{3}$ spectral data.

\section{Results and Discussion}

The experimental data (MS, MS/MS and $\mathrm{MS}^{3}$ ) of atorvastatin was generated using a high performance liquid chromatography (HPLC) coupled with Q-trap and Q-ToF mass spectrometer system; via Flow Injection Analysis (FIA) mode and Electro-spray Ionization ( $\mathrm{ESI}^{-}$) ion source.

The full scan MS and product ion spectrum of atorvastatin was obtained from MS, product ion (MS/MS) and MS ${ }^{3}$ experiments. The workflow [18] and other 
basic mass spectrometric interpretation rules were applied for the interpretation of MS, MS/MS and $\mathrm{MS}^{3}$ spectral data.

De-protonated parent ion $[\mathrm{M}-\mathrm{H}]^{-}$at $\mathrm{m} / z 557.3 \mathrm{u}$, from MS scan displayed in Figure 1, negative mode MS/MS spectrum of atorvastatin also exhibited de-protonated ion peak (about; 1.5\%) at $\mathrm{m} / \mathrm{z} 557.2 \mathrm{u}$ as $[\mathrm{M}-\mathrm{H}]^{-}$(for elemental composition $\mathrm{C}_{33} \mathrm{H}_{34} \mathrm{FN}_{2} \mathrm{O}_{5}^{-}$, calculated monoisotopic $557.2 \mathrm{u}$ ). It was fragmented in collision cell (Q2), into four major fragments at $\mathrm{m} / z 479.3$ (F1; about 2.5\%), 453.2 (F2; about 17.4\%), 397.2 (F3; about 61.3\%) and 278.1 (F4; about 17.2\%) as presented in Figure 2.

Interpretation for these four fragments (F1, F2, F3 and F4) carried out and data presented in Figure 3. Assigned molecular structures, elemental compositions and calculated molecular weight structures of MS/MS fragments were illustrated in Table 1 and Figure 3; pathways was assigned using MS/MS and MS data, described later in this section, mechanism for formation of fragments presented in Figures 4-20. Product ion $\mathrm{m} / z$ 479.3 (F1) (calculated formula $\mathrm{C}_{31} \mathrm{H}_{28} \mathrm{FN}_{2} \mathrm{O}_{2}^{-}$, calculated monoisotopic molecular mass 479.2) formed by loss of water $\left(\mathrm{H}_{2} \mathrm{O}\right)$, loss of $\mathrm{C}_{2} \mathrm{H}_{3} \mathrm{O}_{2}^{-}$and loss of $\mathrm{H}_{2}$, refer Figure 4; product ion $\mathrm{m} / \mathrm{Z}$ 453.3 (F2) (calculated formula $\mathrm{C}_{29} \mathrm{H}_{26} \mathrm{FN}_{2} \mathrm{O}_{2}^{-}$, calculated monoisotopic molecular

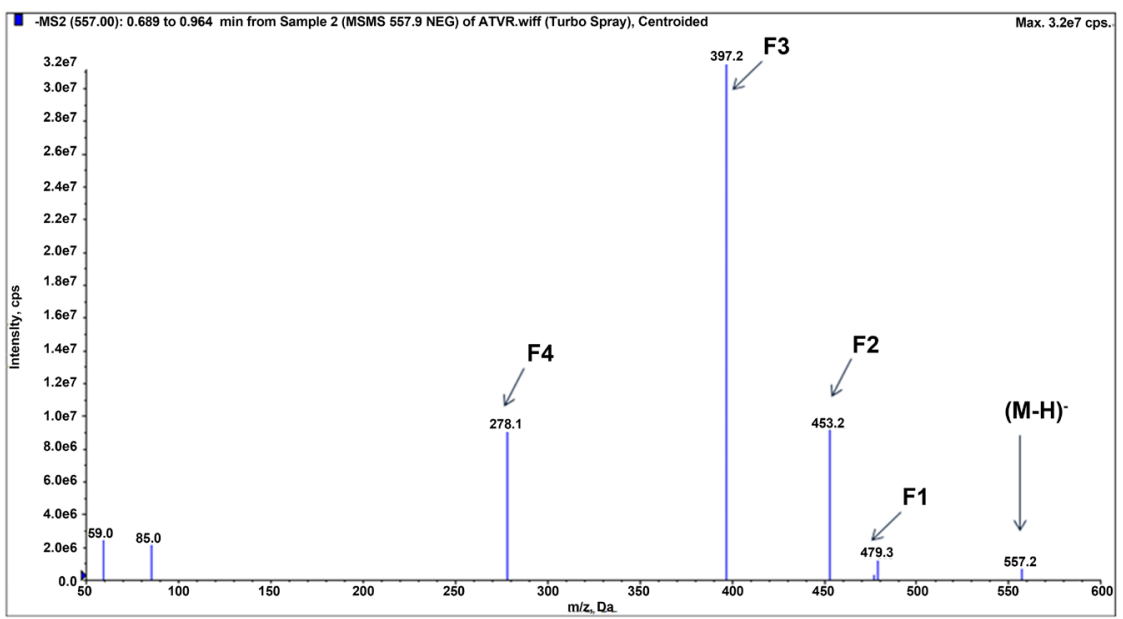

Figure 2. MS/MS spectra of parent ion $\mathrm{m} / z 557$.

Table 1. Interpretation of MS/MS of atorvastatin based on rational work flow.

\begin{tabular}{ccccccc}
\hline $\begin{array}{c}\text { Observed Mass } \\
(\boldsymbol{m} / \boldsymbol{z})^{\mathbf{a}}\end{array}$ & ID & $\begin{array}{c}\text { Electron } \\
\text { Paring }\end{array}$ & $\begin{array}{c}\text { Nitrogen } \\
\text { Rule }\end{array}$ & $\begin{array}{c}\text { No. of Nitro- } \\
\text { gen }(\mathbf{s})\end{array}$ & $\begin{array}{c}\text { Proposed } \\
\text { Formula }\end{array}$ & $\begin{array}{c}\text { Theoretical Mass } \\
(\boldsymbol{m} / \boldsymbol{z})\end{array}$ \\
\hline 557.2 & Parent & {$[\mathrm{M}-\mathrm{H}]^{-}$} & $\mathrm{EN}$ & 2 & $\mathrm{C}_{33} \mathrm{H}_{34} \mathrm{FN}_{2} \mathrm{O}_{5}^{-}$ & 557.2 \\
479.3 & F1 & EE & EN & 2 & $\mathrm{C}_{31} \mathrm{H}_{28} \mathrm{FN}_{2} \mathrm{O}_{2}^{-}$ & 479.2 \\
453.2 & F2 & EE & EN & 2 & $\mathrm{C}_{29} \mathrm{H}_{26} \mathrm{FN}_{2} \mathrm{O}_{2}^{-}$ & 453.2 \\
397.2 & F3 & EE & EN & 2 & $\mathrm{C}_{26} \mathrm{H}_{22} \mathrm{FN}_{2} \mathrm{O}^{-}$ & 397.2 \\
278.1 & F4 & EE & ON & 1 & $\mathrm{C}_{19} \mathrm{H}_{17} \mathrm{FN}^{-}$ & 278.1 \\
\hline
\end{tabular}

a: Mass acquired with quadrupole mass analyzer unit resolution; b: Monoisotopic theoretical mass. EE: even electron; EN: even nitrogen; ON: odd nitrogen; ID: Identification; $\mathrm{m} / \mathrm{z}=$ mass-to-charge ratio. 




Figure 3. Proposed fragmentation pathway for fragment ion F1, F2, F3 and F4 of atorvastatin based on $\mathrm{MS}^{2}$ and $\mathrm{MS}^{3}$ spectral data.

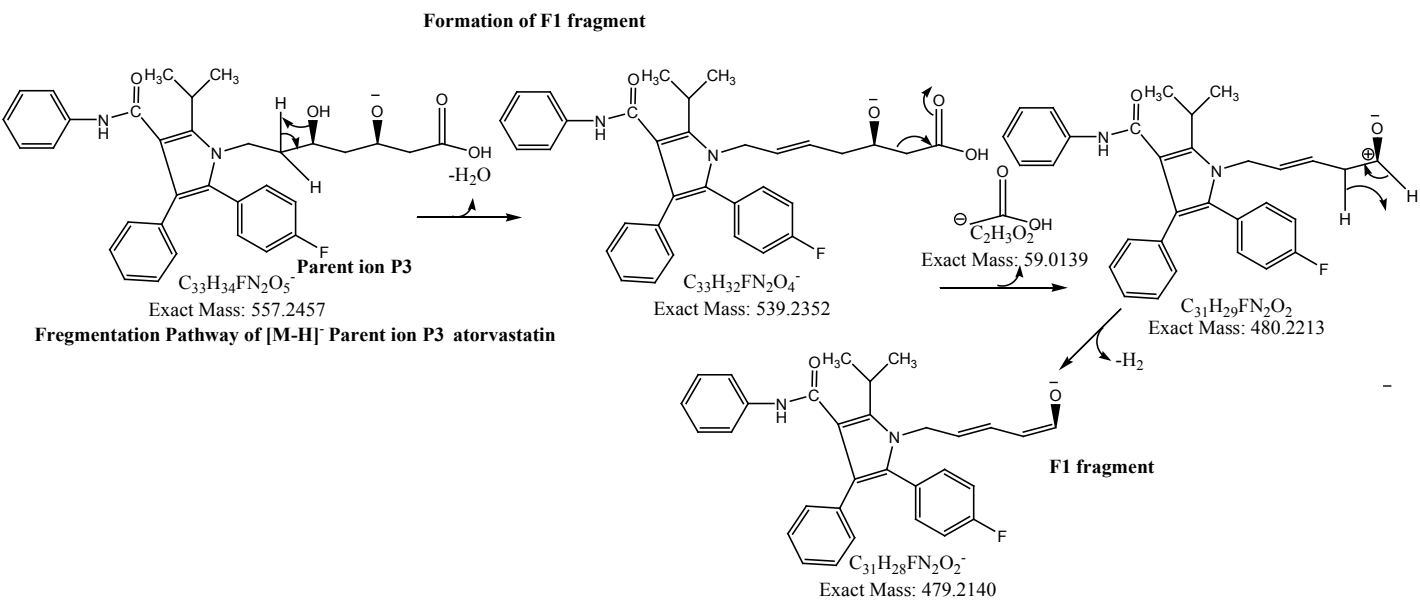

Figure 4. Mechanism for formation of fragment F1.

mass 453.2) formed by loss of $\mathrm{C}_{2} \mathrm{H}_{3} \mathrm{O}_{2}^{-}, \mathrm{C} 2 \mathrm{H}_{3} \mathrm{O}^{-}$and $\mathrm{H}_{2}$, refer Figure 5; product ion $\mathrm{m} / \mathrm{z} 397.2$ (F3) (calculated formula $\mathrm{C}_{26} \mathrm{H}_{22} \mathrm{FN}_{2} \mathrm{O}^{-}$, calculated monoisotopic molecular mass 397.2) produced for product ion $\mathrm{F} 1$ and $\mathrm{F} 2$ by the loss of $\mathrm{C}_{5} \mathrm{H}_{6} \mathrm{O}$ and $\mathrm{C}_{3} \mathrm{H}_{4} \mathrm{O}$ respectively, refer Figure 6. Product ion $\mathrm{m} / z$ 278.1 (F4) (calculated formula $\mathrm{C}_{19} \mathrm{H}_{17} \mathrm{FN}^{-}$, calculated monoisotopic molecular mass 278.1) formed by the loss of $\mathrm{C}_{7} \mathrm{H}_{5} \mathrm{NO}$, refer Figure 7 .

To understand the pathway in detail MS3 analysis of fragment ions (F1, F2, F3 


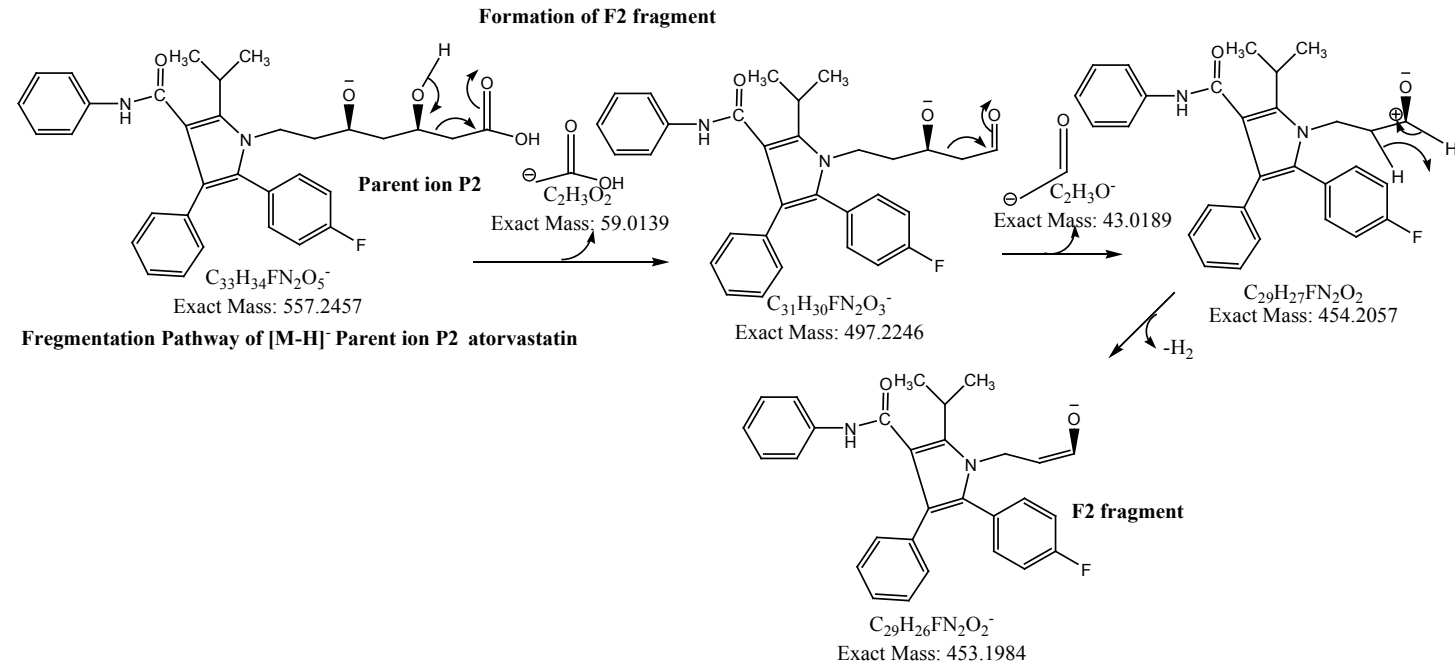

Figure 5. Mechanism for formation of fragment F2.

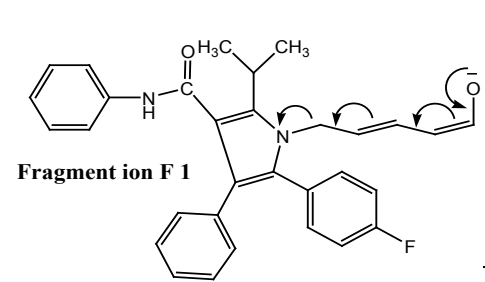

Formation of F3 fragment
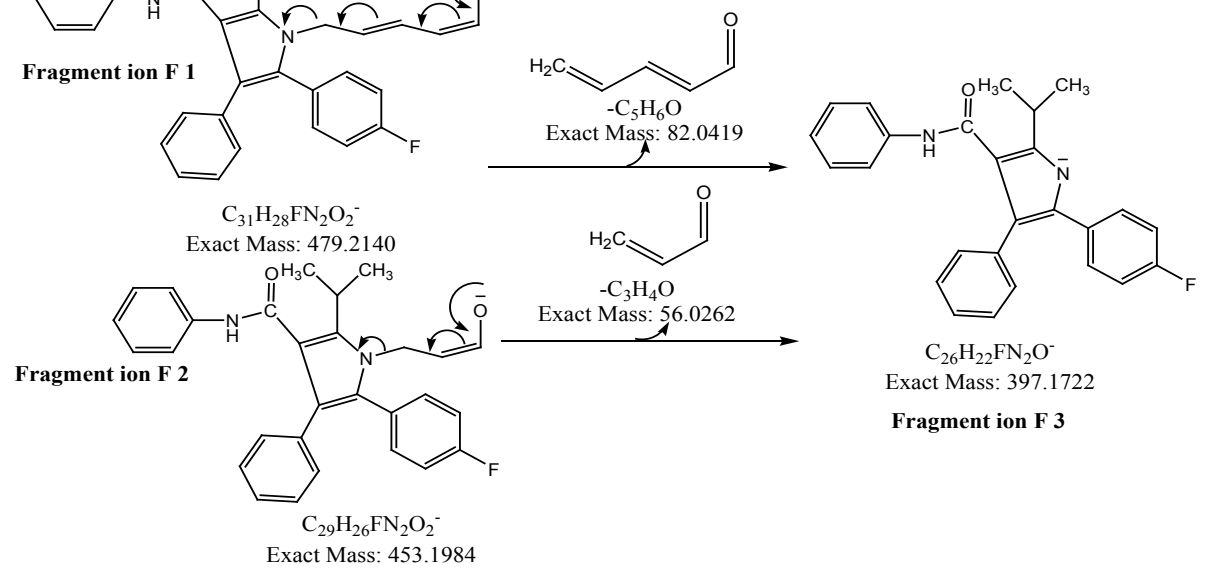

$\mathrm{C}_{26} \mathrm{H}_{22} \mathrm{FN}_{2} \mathrm{O}^{-}$

Exact Mass: 397.1722

Fragment ion F 3

Figure 6. Mechanism for formation of fragment F3.

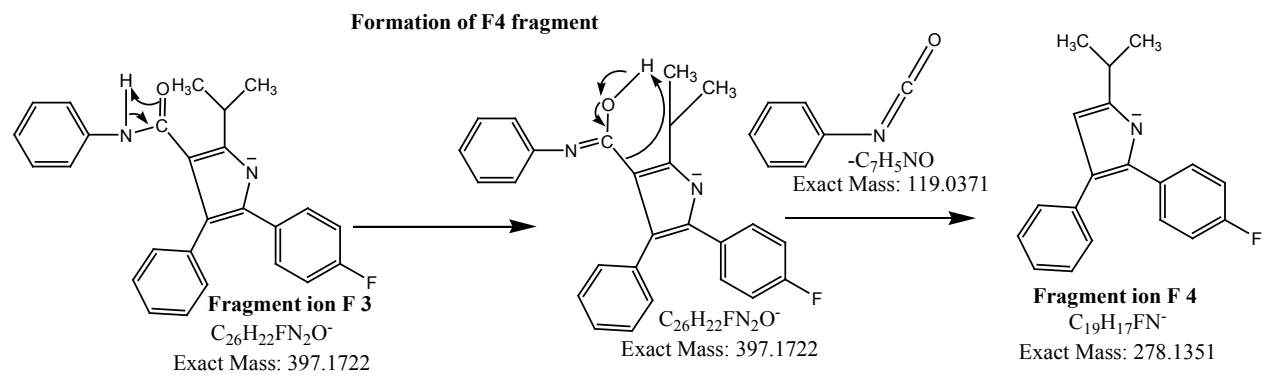

Figure 7. Mechanism for formation of fragment F4.

and F4) was carried out for product ions $m / z$ 479.2, 453.2, 397.2 and $278.1 \mathrm{MS}^{3}$ spectral data of aforesaid product ions is present in Figures 8-11. Interpretation of $\mathrm{MS}^{3}$ spectral data was presented in Table 2 fragmentation pathway presented in Figure 12 \& Figure 13. And mechanism of formation of all $\mathrm{MS}^{3}$ fragment ions presented in Figures 14-20. During $\mathrm{MS}^{3}$ analysis production $\mathrm{F} 1(\mathrm{~m} / \mathrm{z}$ 


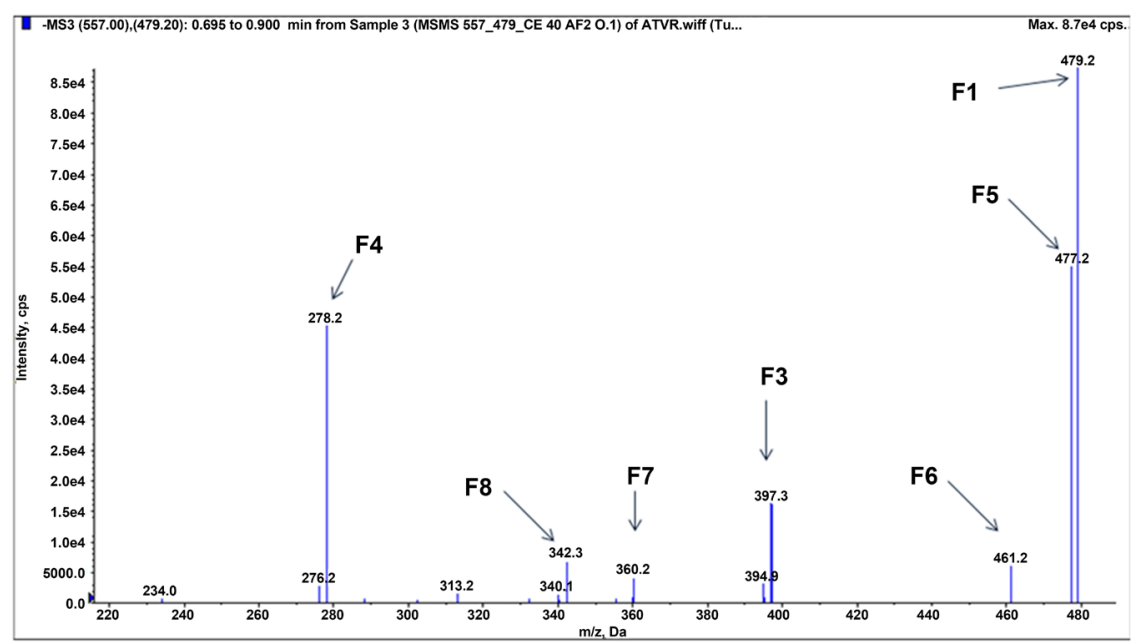

Figure 8. $\mathrm{MS}^{3}$ spectra of product ion $\mathrm{m} / \mathrm{Z} 479.20$ (557.0).

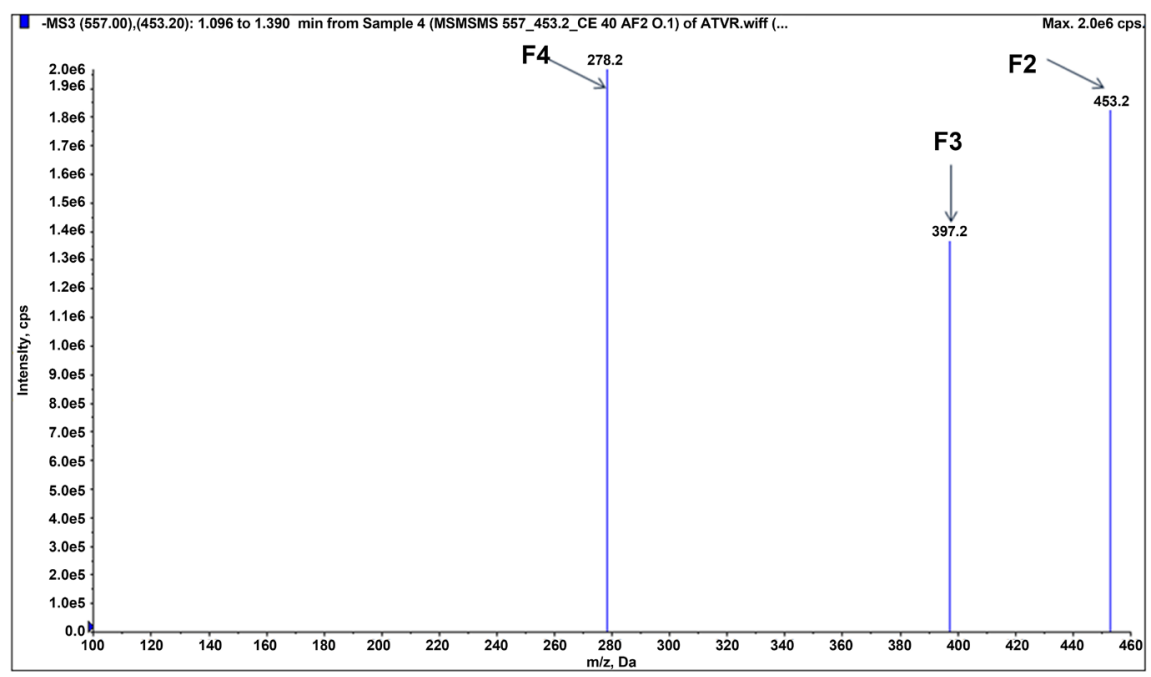

Figure 9. $\mathrm{MS}^{3}$ spectra of product ion $\mathrm{m} / z 453.20$ (557.0).

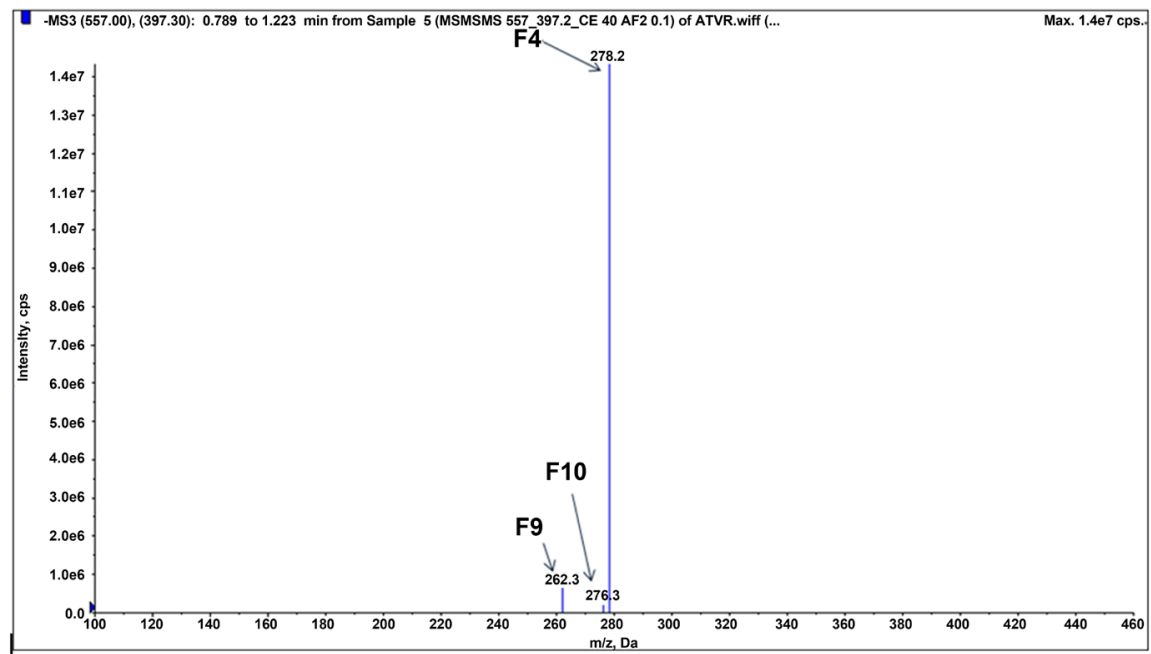

Figure 10. $\mathrm{MS}^{3}$ spectra of product ion $\mathrm{m} / z 397.2$ (557.0). 




Figure 11. MS3 spectra of product ion $\mathrm{m} / \mathrm{z} 278.10$ (557.0).

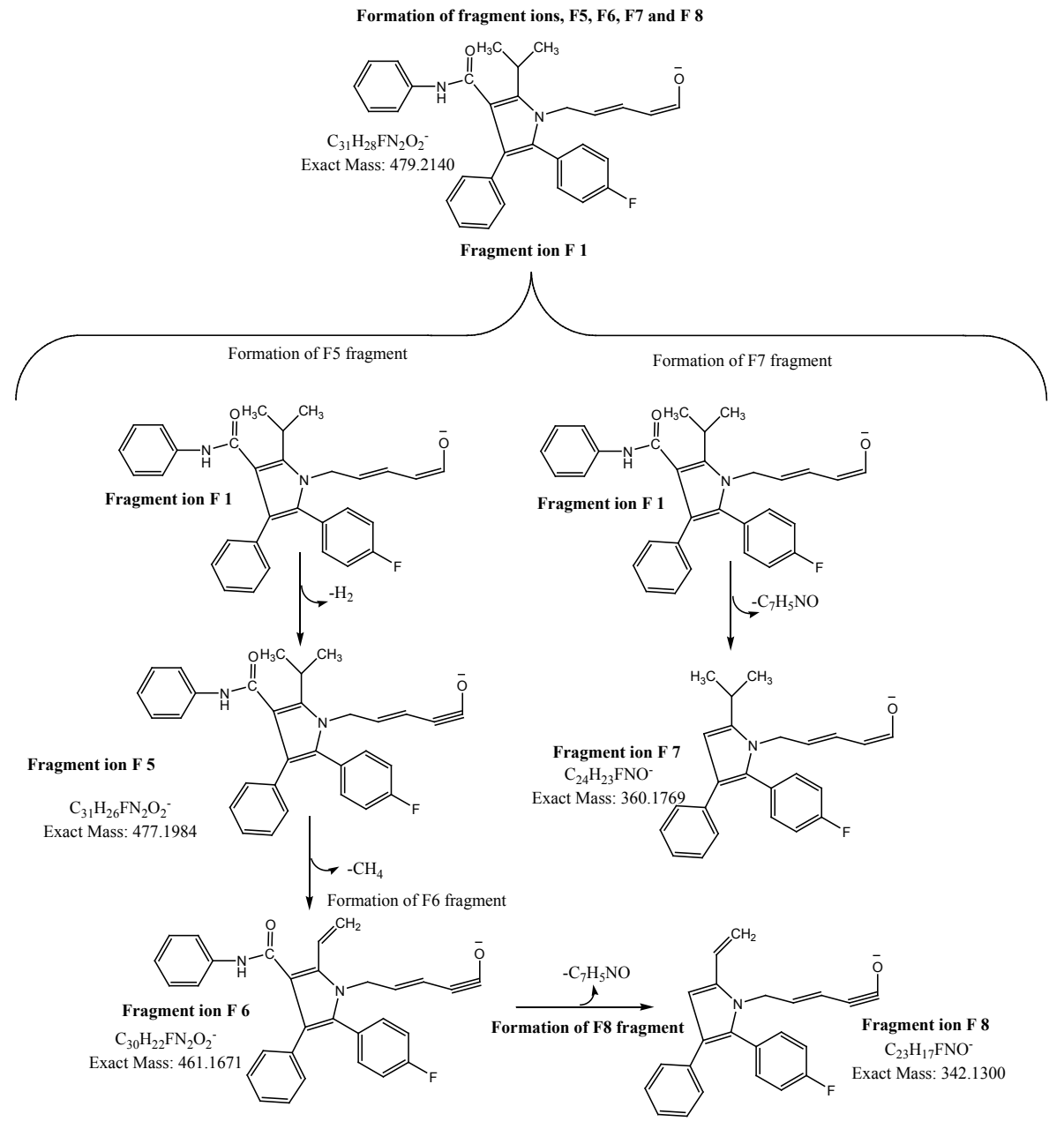

Figure 12. Proposed fragmentation pathway for fragment ion F5, F6, F7 and F8 of atorvastatin based on $\mathrm{MS}^{3}$ spectral data. 
Table 2. Interpretation of $\mathrm{MS}^{3}$ spectra of atorvastatin based on rational work flow.

\begin{tabular}{|c|c|c|c|c|c|c|c|}
\hline $\begin{array}{c}\text { Observed } \\
\text { Mass }(m / z)^{\mathrm{a}} \\
(\mathrm{MS} / \mathrm{MS})\end{array}$ & ID & $\begin{array}{c}\text { Measured } \\
\text { Mass }(m / z) \\
\left(\mathrm{MS}^{3}\right)\end{array}$ & $\begin{array}{c}\text { Electron } \\
\text { Paring }\end{array}$ & $\begin{array}{c}\text { Nitrogen } \\
\text { Rule }\end{array}$ & $\begin{array}{c}\text { No. of } \\
\text { Nitrogen } \\
\text { (s) }\end{array}$ & $\begin{array}{l}\text { Proposed } \\
\text { Formula }\end{array}$ & $\begin{array}{l}\text { Theoretical } \\
\text { Mass }^{\mathrm{b}}(\mathrm{m} / \mathrm{z})\end{array}$ \\
\hline & F5 & 477.2 & $\mathrm{EE}$ & EN & 2 & $\mathrm{C}_{31} \mathrm{H}_{26} \mathrm{FN}_{2} \mathrm{O}_{2}^{-}$ & 477.2 \\
\hline & F6 & 461.2 & $\mathrm{EE}$ & $\mathrm{EN}$ & 2 & $\mathrm{C}_{30} \mathrm{H}_{22} \mathrm{FN}_{2} \mathrm{O}_{2}^{-}$ & 461.2 \\
\hline $479.3(\mathrm{~F} 1)$ & F3 & 397.3 & $\mathrm{EE}$ & ON & 2 & $\mathrm{C}_{26} \mathrm{H}_{22} \mathrm{FN}_{2} \mathrm{O}^{-}$ & 397.2 \\
\hline \multirow[t]{3}{*}{$\mathrm{C}_{31} \mathrm{H}_{28} \mathrm{FN}_{2} \mathrm{O}_{2}^{-}$} & F7 & 360.2 & $\mathrm{EE}$ & ON & 1 & $\mathrm{C}_{24} \mathrm{H}_{23} \mathrm{FNO}^{-}$ & 360.2 \\
\hline & F8 & 342.3 & $\mathrm{EE}$ & ON & 1 & $\mathrm{C}_{23} \mathrm{H}_{17} \mathrm{FNO}^{-}$ & 342.1 \\
\hline & $\mathrm{F} 4$ & 278.2 & $\mathrm{EE}$ & ON & 1 & $\mathrm{C}_{19} \mathrm{H}_{17} \mathrm{FN}^{-}$ & 278.1 \\
\hline $453.2(\mathrm{~F} 2)$ & F3 & 397.2 & $\mathrm{EE}$ & $\mathrm{EN}$ & 2 & $\mathrm{C}_{26} \mathrm{H}_{22} \mathrm{FN}_{2} \mathrm{O}^{-}$ & 397.2 \\
\hline $\mathrm{C}_{29} \mathrm{H}_{26} \mathrm{FN}_{2} \mathrm{O}_{2}^{-}$ & $\mathrm{F} 4$ & 278.2 & $\mathrm{EE}$ & ON & 1 & $\mathrm{C}_{19} \mathrm{H}_{17} \mathrm{FN}^{-}$ & 278.1 \\
\hline $397.2(\mathrm{~F} 3)$ & $\mathrm{F} 4$ & 278.2 & $\mathrm{EE}$ & ON & 1 & $\mathrm{C}_{19} \mathrm{H}_{17} \mathrm{FN}^{-}$ & 278.1 \\
\hline $\mathrm{C}_{26} \mathrm{H}_{22} \mathrm{FN}_{2} \mathrm{O}^{-}$ & F9 & 262.2 & $\mathrm{EE}$ & ON & 1 & $\mathrm{C}_{18} \mathrm{H}_{13} \mathrm{FN}^{-}$ & 262.1 \\
\hline $278.1(\mathrm{~F} 4)$ & F10 & 276.2 & $\mathrm{EE}$ & ON & 1 & $\mathrm{C}_{19} \mathrm{H}_{15} \mathrm{FN}^{-}$ & 276.1 \\
\hline $\mathrm{C}_{19} \mathrm{H}_{17} \mathrm{FN}^{-}$ & F9 & 262.2 & $\mathrm{EE}$ & ON & 1 & $\mathrm{C}_{18} \mathrm{H}_{13} \mathrm{FN}^{-}$ & 262.1 \\
\hline
\end{tabular}

a: Mass acquired with quadrupole mass analyzer unit resolution; b: Monoisotopic theoretical mass. EE: even electron; EN: even nitrogen; ON: odd nitrogen; ID: Identification; $\mathrm{m} / \mathrm{z}=$ mass-to-charge ratio.

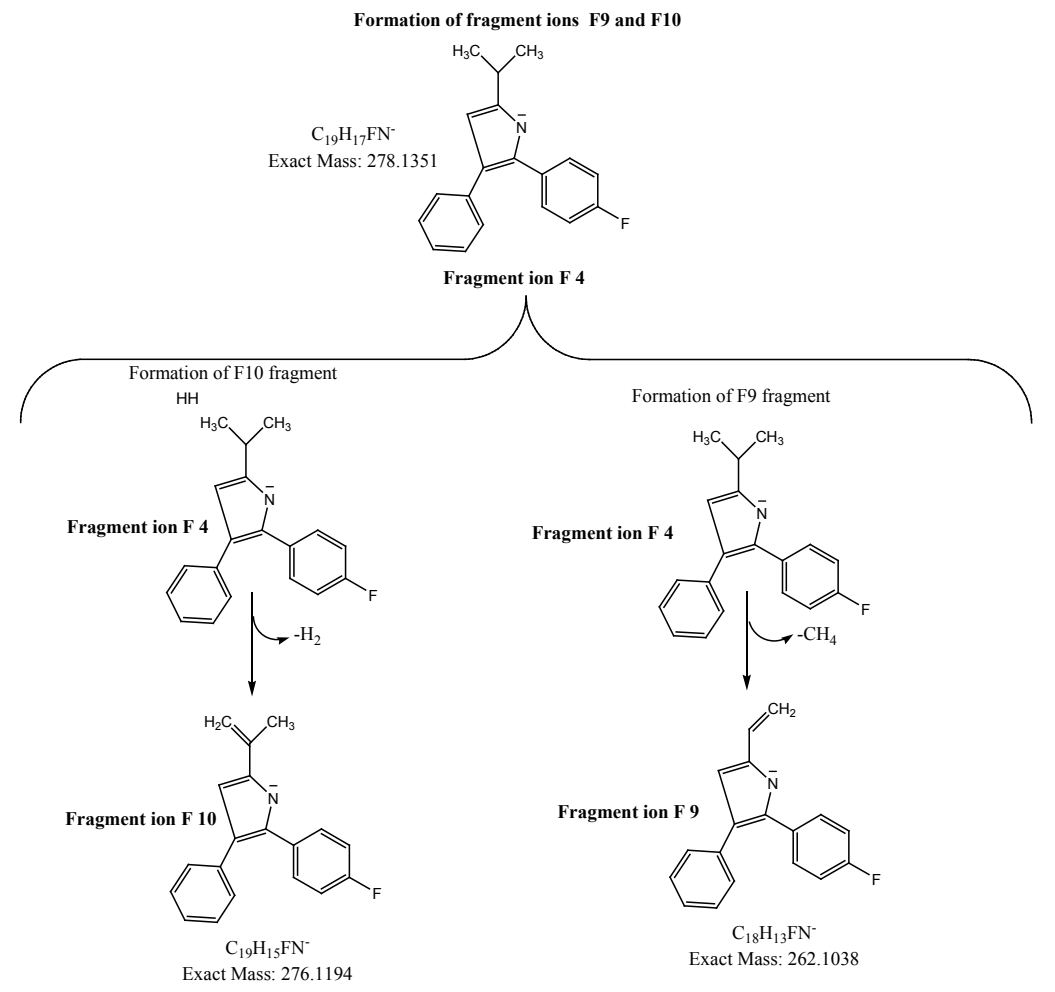

Figure 13. Proposed fragmentation pathway for fragment ion F9 and F4 of atorvastatin based on $\mathrm{MS}^{3}$ spectral data.

479.3) - fragmented into six fragments, refer Figure 8; two fragments are common with MS/MS analysis $\mathrm{F} 3(\mathrm{~m} / z$ 397.3) and $\mathrm{F} 4(\mathrm{~m} / z$ 278.2), remaining four fragments are new fragments named as $m / z 477.2$ (F5), 461.2 (F6), 360.2 (F7) 
and 342.3 (F8). Fragment ion F2 ( $\mathrm{m} / z$ 453.2) - fragmented into two fragments, refer Figure 13; F3 $(\mathrm{m} / z$ 397.3) and F4 $(\mathrm{m} / z$ 278.2), both fragment are discussed during MS/MS data interpretation. As shown is Figure 10, fragment ion F3 $(\mathrm{m} / z$ 397.3) - fragmented into two fragments $\mathrm{F} 4(\mathrm{~m} / z$ 278.2) and F9 $(\mathrm{m} / z$ 262.2) fragment F4 same as MS/MS analysis and one new fragment F9. Fragment ion F4 $(\mathrm{m} / z$ 278.2) fragmented into two new fragments refer Figure 11, F9 $(\mathrm{m} / z$ 276.2) and F10 $\left(\mathrm{m} / z\right.$ 262.2). So, during $\mathrm{MS}^{3}$ data interpretation six new fragment was observed, when compared with MS/MS analysis data. Formation of fragments F6 to F10 presented in Figure 12 \& Figure 13 and mechanism for formation of fragments presented in Figures 14-19. And also summarized in few words as; Fragment F5 ( $m / z$ 477.2, calculated formula $\mathrm{C}_{31} \mathrm{H}_{26} \mathrm{FN}_{2} \mathrm{O}_{2}^{-}$, calculated monoisotopic molecular mass 477.2) produced by the loss of $\mathrm{H}_{2}$ from fragment ion $\mathrm{F} 1(\mathrm{~m} / z$ 479.2) refer Figure 14; source of fragment ion $\mathrm{F} 6(\mathrm{~m} / z$ 461.2, calculated formula $\mathrm{C}_{30} \mathrm{H}_{22} \mathrm{FN}_{2} \mathrm{O}_{2}^{-}$, calculated monoisotopic molecular mass 466.2$)$ is $\mathrm{F} 5(\mathrm{~m} / z 477.2)$ produced by loss of $\mathrm{CH}_{4}$, refer Figure 16. Fragment ion F8 $(\mathrm{m} / z 342.3$, calculated

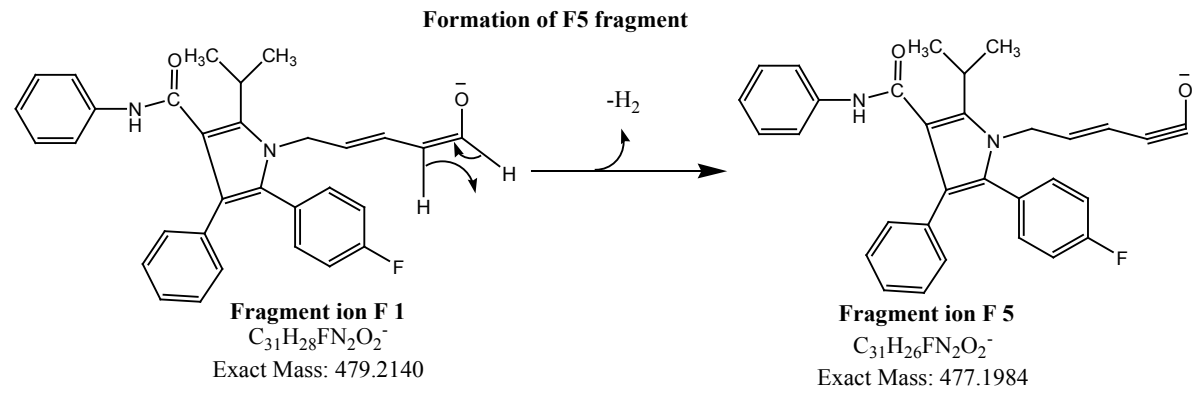

Figure 14. Mechanism for formation of fragment F5.

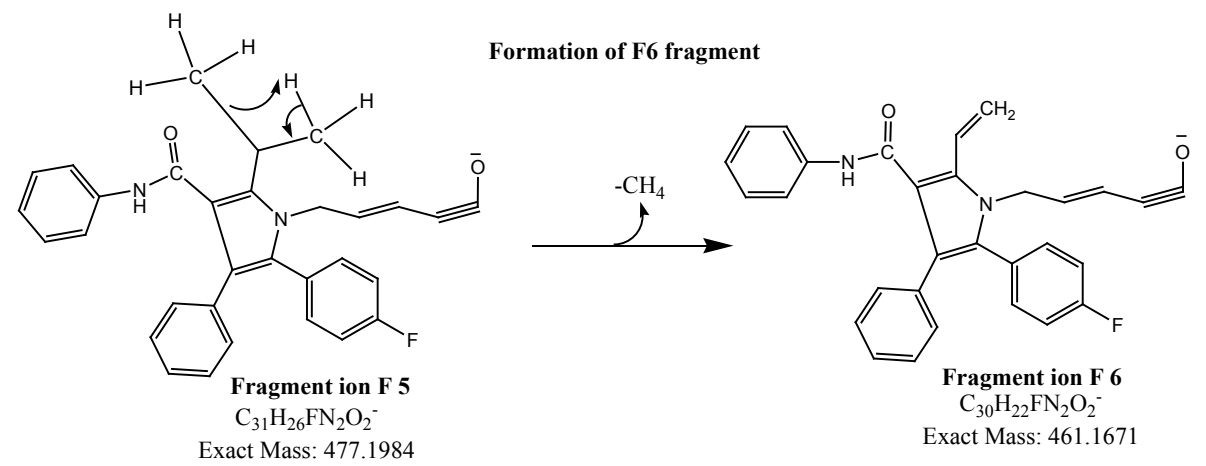

Figure 15. Mechanism for formation of fragment F6.

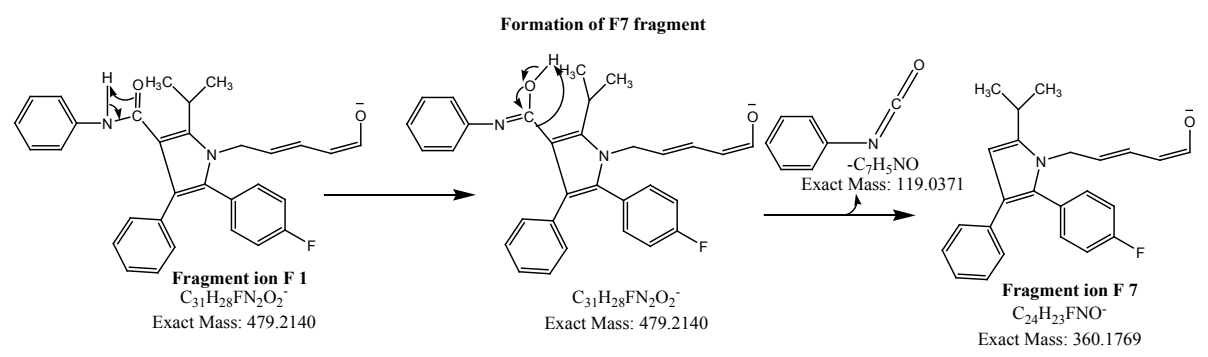

Figure 16. Mechanism for formation of fragment F7. 


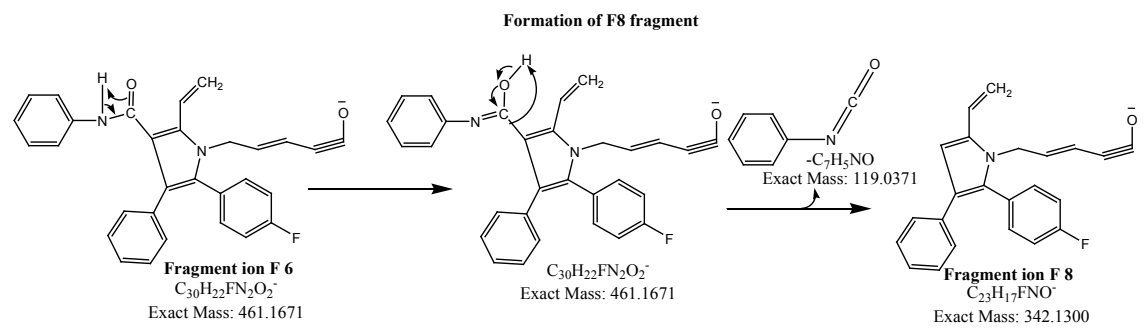

Figure 17. Mechanism for formation of fragment F8.



Exact Mass: 278.1351

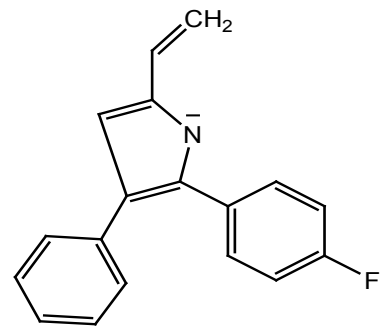

Fragment ion F 9

$\mathrm{C}_{18} \mathrm{H}_{13} \mathrm{FN}^{-}$

Exact Mass: 262.1038

Figure 18. Mechanism for formation of fragment F9.

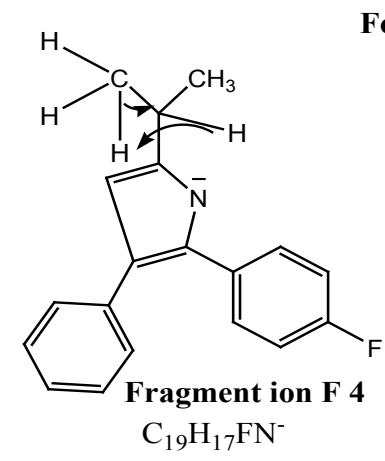

Exact Mass: 278.1351
Formation of F10 fragment

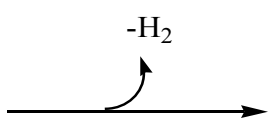

Fragment ion $\mathbf{F} 10$ $\mathrm{C}_{19} \mathrm{H}_{15} \mathrm{FN}^{-}$

Figure 19. Mechanism for formation of fragment F10.

formula $\mathrm{C}_{23} \mathrm{H}_{17} \mathrm{FNO}^{-}$, calculated monoisotopic molecular mass 342.1) formed from F6 fragment after loss of $\mathrm{C}_{7} \mathrm{H}_{5} \mathrm{NO}$, refer Figure 17. Fragment ion F7 $(\mathrm{m} / \mathrm{z}$ 360.2, calculated formula $\mathrm{C}_{24} \mathrm{H}_{23} \mathrm{FNO}^{-}$, calculated monoisotopic molecular mass 360.2) formed from fragment $\mathrm{F} 1$ by loss of $\mathrm{C}_{7} \mathrm{H}_{5} \mathrm{NO}$, refer Figure 16. Fragment ion $\mathrm{F} 9\left(\mathrm{~m} / z 262.2\right.$, calculated formula $\mathrm{C}_{18} \mathrm{H}_{13} \mathrm{FN}^{-}$, calculated monoisotopic molecular mass 262.1) and $\mathrm{F} 10\left(\mathrm{~m} / z\right.$ 276.2, calculated formula $\mathrm{C}_{19} \mathrm{H}_{15} \mathrm{FN}^{-}$, calculated monoisotopic molecular mass 276.1) formed by loss of $\mathrm{H}_{2}$ and $\mathrm{CH}_{4}$ from fragment ion F4 respectively, refer Figure 18 and Figure 19. MS and MS/MS data described in the above section acquired using quadrupole mass analyzer; error ppm not calculated. As an additional verification, to support proposed elemental composition of common fragments compared with HR-MS/MS measured $\mathrm{m} / \mathrm{z}$ values (Figure 20), and ppm error presented in Table 3. 
Table 3. Comparison of proposed elemental composition with High resolution MS/MS data.

\begin{tabular}{ccccc}
\hline $\begin{array}{c}\text { Observed accurate } \\
(\boldsymbol{m} / \boldsymbol{z})^{\mathbf{c}}\end{array}$ & ID & Proposed Formula & $\begin{array}{c}\text { Theoretical accu- } \\
\text { rate Mass }{ }^{\mathbf{b}}(\boldsymbol{m} / \boldsymbol{z})\end{array}$ & ${\text { Error }(\mathbf{p p m})^{\mathrm{d}}}$ \\
\hline 557.24350 & Parent & $\mathrm{C}_{33} \mathrm{H}_{34} \mathrm{FN}_{2} \mathrm{O}_{5}^{-}$ & 557.2457 & -4 \\
453.19515 & $\mathrm{~F} 2$ & $\mathrm{C}_{29} \mathrm{H}_{26} \mathrm{FN}_{2} \mathrm{O}_{2}^{-}$ & 453.1984 & -7 \\
397.17220 & $\mathrm{~F} 3$ & $\mathrm{C}_{26} \mathrm{H}_{22} \mathrm{FN}_{2} \mathrm{O}^{-}$ & 397.1722 & 0 \\
278.13903 & F4 & $\mathrm{C}_{19} \mathrm{H}_{17} \mathrm{FN}^{-}$ & 278.1351 & 14 \\
262.10266 & F9 & $\mathrm{C}_{18} \mathrm{H}_{13} \mathrm{FN}^{-}$ & 262.1038 & -4.3 \\
\hline
\end{tabular}

c: Mass acquired with high resolution; b: Monoisotopic calculated mass; $d$ : Mass error = theoretical accurate mass - observed accurate mass/theoretical accurate mass $\times 10^{6}$. EE: even electron; EN: even nitrogen; ON: odd nitrogen; ID: Identification; $\mathrm{m} / \mathrm{z}=$ mass-to-charge ratio.

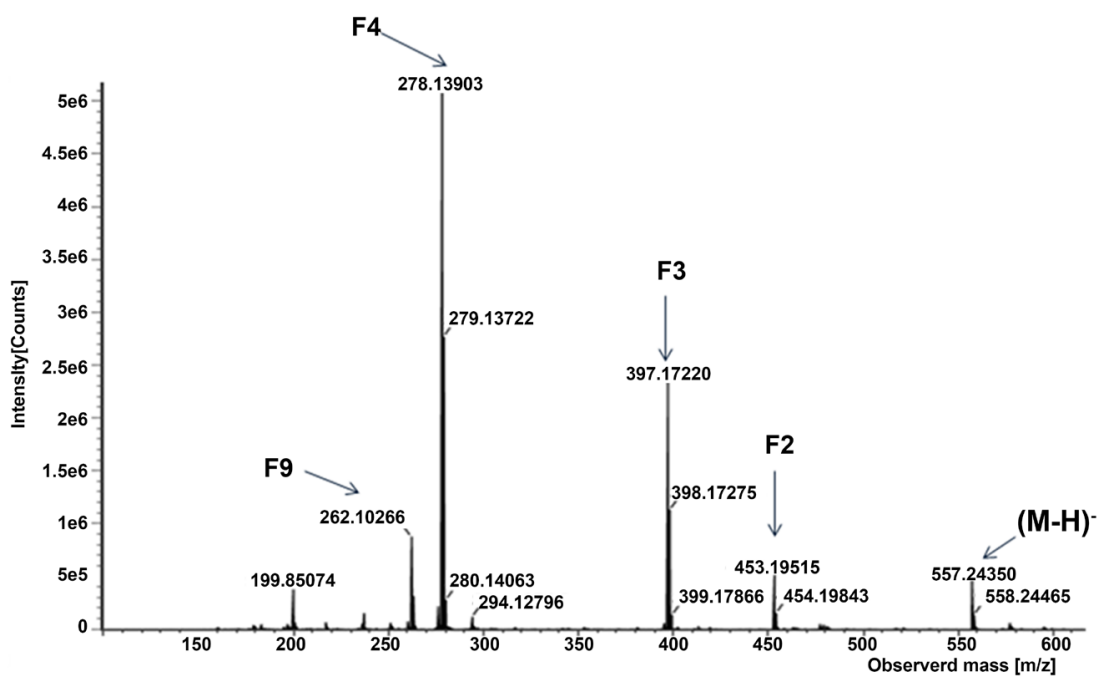

Figure 20. HR-MS/MS spectra of atorvastatin deprotonated ion.

\section{Conclusion}

This study and rational manual data interpretation workflow can be useful for writing fragmentation pathway, the mechanism for the formation of fragments, and can be applied for mass spectral data interpretation of small organic molecules with similar functional groups. The de-protonated ion peak as $[\mathrm{M}-\mathrm{H}]^{-}$of atorvastatin appeared at $\mathrm{m} / z 557.3$ u. Further, the CID fragmentation of de-protonated $[\mathrm{M}-\mathrm{H}]^{-}$ion generated, and interpretation was carried followed by the proposal of fragmentation pathway; based on neutral losses, charge sites activated fragmentation, elimination reactions, single and multiple bond cleavages. Various software tools are available for the interpretation of mass spectrometry data; during the study, no software tool was used for interpretation, predication of the fragments structure and pathway of formation. In addition to above, the study also provides the insights about the in-depth structural analysis study for small organic molecules and manual workflow based interpretation of parent and product ion spectra in combination with the basic rules. The workflow ap- 
plied in this study was found efficient and can be applied to similar structure verification studies.

\section{Acknowledgements}

This paper is part of Ph.D thesis of Dev Kant Shandilya. Author expresses his gratitude to the Dean, Department of Research, Bhagwant University, Ajmer, Rajasthan, India for extending his constant support.

\section{Conflicts of Interest}

Declared none.

\section{Abbreviations Used}

LC: Liquid chromatography; HPLC: High performance liquid chromatography; MS: Mass spectrometry; HR: High resolution; MS/MS: Tandem mass spectrometer; $\mathrm{MS}^{3}$ : Tandem mass spectrometer with trap functionality; $\mathrm{m} / \mathrm{z}$. mass-to-charge ratio; API: Atmospheric pressure ionization; APCI: Atmospheric pressure chemical ionization; ESI: Electrospray ionization; CID: Collision-induced dissociation; FIA: Flow injection analysis.

\section{References}

[1] Aksenov, A.A., da Silva, R., Knight, R., Lopes, N.P. and Dorrestein, P.C. (2017) Global Chemical Analysis of Biology by Mass Spectrometry: Nature Reviews Chemistry. Nature Reviews Chemistry, 1, Article No. 0054.

[2] Domon, B. and Aebersold, R. (2006) Mass Spectrometry and Protein Analysis. Science, 312, 212-217.

[3] Pramanik, B.N., Bartner, P.L. and Chen, G. (1999) The Role of Mass Spectrometry in the Drug Discovery Process. Current Opinion in Drug Discovery \& Development, 2, 401-417.

[4] Nicolas, C.E. and Schoolz, T.H. (1998) Active Drug Substances Impurity Profiling Part II. LC-MS/MS Fingerprinting. Journal of Pharmaceutical and Biomedical Analysis, 16, 825-836. https://doi.org/10.1016/S0731-7085(97)00132-5

[5] Cooks, R.G., Chen, G., Wong, P. and Wollnik, H. (1997) Mass Spectrometers. In: Trigg, G.L., Ed., Encyclopedia of Applied Physics, Vol. 19, VCH Publishers, New York, 289.

[6] Chen, G., Pramanik, B.N., Liu, Y.-H. and Mirza, U.A. (2007) Applications of LC/MS in Structure Identifications of Small Molecules and Proteins in Drug Discovery. Journal of Mass Spectrometry, 42, 279-287. https://doi.org/10.1002/jms.1184

[7] Ermer, J. (1998) The Use of Hyphenated LC-MS Technique for Characterization of Impurity Profiles during Drug Development. Journal of Pharmaceutical and Biomedical Analysis, 18, 707-714. https://doi.org/10.1016/S0731-7085(98)00267-2

[8] McLafferty, F.W. and Turecek, F. (1993) Interpretation of Mass Spectra. University of Science Books, Mill Valley, CA.

[9] Angelika, G., Harrison, M.W., Herniman, J.M., Skylaris, C.-K. and Langely, G.J. (2013) A Predictive Science Approach to Aid Understanding of Electrospray Ionization Trandem Mass Spectrometric Fragmentation Pathway of Small Molecules Us- 
ing Density Fuctional Calculations. Rapid Communications in Mass Spectrometry, 27, 964-970. https://doi.org/10.1002/rcm.6536

[10] Holcapek, M., Jirasko, R. and Lísa, M. (2010) Basic Rules for the Interpretation of Atmospheric Pressure Ionization Mass Spectra of Small Molecules. Chromatography A, 1217, 3908-3921. https://doi.org/10.1016/j.chroma.2010.02.049

[11] Johnson, A.R. and Carlson, E.E. (2015) Collision-Induced Dissociation Mass Spectrometry: A Powerful Tool for Natural Product Structure Elucidation. ACS Publications Analytical Chemistry, 87, 10668-10678.

https://doi.org/10.1021/acs.analchem.5b01543

[12] Guan, F.Y., Soma, L.R. and Luo, Y. (2006) Collision-Induced Dissociation Pathways of Anabolic Steroids by Electrospray Ionization Tandem Mass Spectrometry. Journal American Society of Mass Spectrometry, 17, 477-489.

https://doi.org/10.1016/j.jasms.2005.11.021

[13] Dermarque, D.P., Crotti, A.E.M., Vessecchi, R., Lopes, J.L.C. and Lopes, N.P. (2016) Fragmentation Reactions Using Electrospray Ionization Mass Spectrometry: and Important Tool for Structural Elucidation and Characterization of Synthetic and Natural Products. Natural Product Reports, 33, 432.

https://doi.org/10.1039/C5NP00073D

[14] Shandilya, D.K., Joseph, P.E. and Kantamreddi, V.S.S. (2017) Prediction of the Fragmentation Pathway of Atorvastatin by Using High Resolution Collision Induced Dissociation (HR-MS/MS) Spectral Data. Open Access Library Journal, 4, e3473. https://doi.org/10.4236/oalib.1103473

[15] https://en.wikipedia.org/wiki/Atorvastatin

[16] http://www.drugs.com/atorvastatin.html

[17] http://www.rxlist.com/lipitor-drug.htm

[18] Shandilya, D.K., Joseph, P.E. and Kantamreddi, V.S.S. (2017) Interpretation of Full Scan Atmospheric Pressure Ionization Mass Spectra (MS) and Collision Induced Dissociation Fragmentation Spectra (MS/MS) of Small Organic Molecules-A Mini Review. Systematic Reviews in Pharmacy, 8, 23-25. 